\title{
La evolución de las relaciones entre los socios originarios del MERCOSUR y sus pares del CCG. Una mirada desde el Cono Sur (2005-2015)
}

\begin{abstract}
Ornela Fabani ${ }^{1}$
UNR - CONICET -CERIR

\section{Artículo científico}

Material original autorizado para su primera publicación en el Journal de Ciencias Sociales, Revista Académica de la Facultad de Ciencias Sociales de la Universidad de Palermo.
\end{abstract}

\section{Recibido: 1-3-2016 \\ Aceptado: 26-10-2016}

Resumen: El objetivo de este artículo reside en analizar la evolución de los vínculos político-diplomáticos, económicocomerciales y estratégico-militares entre los cuatro miembros originarios del MERCOSUR y sus pares del CCG, así como también los factores que explican los mismos, entre 2005 y 2015 . Mientras tanto, nuestro supuesto de partida radica en que, en primer lugar, los vínculos bilaterales entre este conjunto de actores han presentado divergencias en cuanto a su densidad, destacándose las relaciones de Brasil y Argentina para con sus contrapartes árabes. En segundo lugar, los vínculos político-diplomáticos y económico-comerciales han evolucionado en mayor medida que aquellos estratégico-militares. En tanto, entre los factores que han favorecido el acercamiento entre las partes se destacan las cumbres ASPA, impulsadas por el gobierno brasileño, y la crisis financiera internacional, como asimismo la búsqueda de los actores sudamericanos de diversificar mercados y captar inversiones, que se suma a la necesidad de las monarquías del Golfo de garantizar su seguridad alimentaria y efectuar avances en términos de cooperación tecnológica. Por último, pretendemos avanzar en la exploración del devenir de estos lazos atendiendo a diversas fuentes secundarias -principalmente artículos de prensa nacional e internacional-, pero también primarias declaraciones oficiales, comunicados de prensa e informes estadísticos-.

Palabras clave: miembros originarios del MERCOSUR, socios del Consejo de Cooperación del Golfo, relaciones bilaterales, cooperación sur-sur.

\section{The evolution of the relationship between MERCOSUR original partners and its counterparts in the GCC. A view} from the South Cone (2005-2015)

Abstract: The aim of this paper is to analyze the evolution of the political-diplomatic, economic-commercial and strategic-military ties among the four original members of MERCOSUR and its GCC peers, as well as the factors that explain them, between 2005 and 2015. Meanwhile, our starting assumption is that, firstly, bilateral links between this set of actors have presented differences in their density, standing relations between Brazil and Argentina and their Arabs counterparts. Second, the political-diplomatic and economic-commercial ties have evolved further than those

\footnotetext{
${ }^{1}$ Consejo Nacional de Investigaciones Científicas y Técnicas (CONICET). Correo electrónico: ornela_fabani@hotmail.com
} 
strategic-military. On the other hand, among the factors that have favored the rapprochement between the parties highlights the ASPA summits, promoted by the Brazilian government, and the international financial crisis. Furthermore, the search of the South American actors to diversify markets and attract investment that adds to the need of the Gulf monarchies to ensure food security and make progress in terms of technological cooperation. Finally, we intend to explore the evolution of these ties taking into consideration various secondary sources -mainly articles in national and international press- but also primary sources-official statements, press releases and statistical reports - .

Key words: MERCOSUR original partners, GCC members, bilateral relations, south-south cooperation.

\section{Introducción}

Históricamente, los estados sudamericanos no han mantenido un vínculo de primera línea con los países que componen el espacio que ha dado en llamarse Medio Oriente. Por el contrario, tradicionalmente las relaciones con los actores que forman parte de dicha región han guardado un lugar secundario en la agenda de política exterior de los países del Cono Sur. En este marco, los lazos entre los miembros originarios del MERCOSUR -Argentina, Brasil, Paraguay y Uruguay- y sus pares del CCG -Arabia Saudita, Bahrein, Kuwait, Omán, Qatar y Emiratos Árabes Unidos (EAU)- no resultan una excepción. De hecho, las monarquías del Golfo ni siquiera se encuentran entre los actores con los cuales los referidos países sudamericanos han mantenido una relación más cercana en lo que respecta a la región en su conjunto. Ahora bien, lo cierto es que estos vínculos de baja densidad comienzan a cobrar impulso a partir de la I Cumbre ASPA en 2005.

El objetivo de este artículo reside en analizar la evolución de los vínculos político-diplomáticos, económicocomerciales y estratégico-militares entre los cuatro miembros originarios del MERCOSUR y sus pares del CCG, así como también los factores que explican los mismos, entre 2005 y 2015 . Vale mencionar que se decidió abordar este periodo en función de que, como ya se hizo referencia, a partir de la I Cumbre ASPA se evidencia un acercamiento entre las partes, el cual, no obstante, se ha profundizado en el último lustro.

Mientras tanto, nuestro supuesto de partida radica, en primer lugar, en que los vínculos bilaterales entre este conjunto de actores han presentado divergencias en cuanto a su densidad, destacándose las relaciones de Brasil y Argentina para con sus contrapartes árabes. En segundo lugar, los vínculos político-diplomáticos y económicocomerciales han evolucionado en mayor medida que aquellos estratégico-militares. En tanto, entre los factores que han favorecido el acercamiento entre las partes se destacan las cumbres ASPA, impulsadas por el gobierno brasileño, y el inicio de crisis la financiera internacional, como también la búsqueda de los actores sudamericanos de diversificar mercados y captar inversiones, que se suma a la necesidad de las monarquías del Golfo de garantizar su seguridad alimentaria y efectuar avances en términos de cooperación tecnológica. 
Dicho esto, resulta necesario mencionar que entendemos a la política exterior como:

un área particular de la acción gubernamental que abarca tres dimensiones analíticamente separables: político-diplomática, militar-estratégica y económica, y que se proyecta en el ámbito externo frente a una amplia gama de actores e instituciones gubernamentales y no gubernamentales, tanto en el plano bilateral como multilateral. (Russell, 1990, p. 255)

Ahora bien, las políticas exteriores de los miembros originarios del MERCOSUR, durante el periodo de referencia, han asignado un espacio de relevancia a la diversificación de los socios y la exploración de nuevo mercados. En esta línea, el canciller argentino Timerman mencionaba:

Tenemos que crear un canal de diálogo directo con los países árabes [...] necesitamos hacer alianzas. Nos tenemos que dar cuenta de que el mundo pasa hoy por otros lugares, que países que hace 20 años no tenían relevancia cada vez empiezan a tomar mayor importancia. (Cibeira, 2011)

Precisamente en este marco se produce el acercamiento de estos países a los Estados del Golfo, que pueden ser referidos como socios no tradicionales, en función de que se trata de actores con los cuales, a través del tiempo, no se han mantenido vínculos sólidos y de primera línea, pero también como socios potenciales en tanto se trata de mercados que en la actualidad poseen una baja relevancia en lo que atañe al volumen de las operaciones, si bien presentan importantes oportunidades para los productos de estos países (Grosso, Moldovan y Todesca, 2009).

Asimismo, este acercamiento debe ser encuadrado en el marco de la cooperación sur-sur entendida como "relaciones directas y horizontales entre países que enfrentan problemas comunes y que tienen como propósito superar, a partir de esfuerzos conjuntos, los desafíos del desarrollo", esto a través de mecanismos tales como el comercio, el intercambio de experiencias exitosas y la inclusión (SELA, 2015). En esta dirección, Ulrichsen (2013) señala que ciertas vías posibles para una fructífera cooperación sur-sur con los Estados del CCG emergen a partir de la búsqueda por parte de estos países de seguridad alimentaria y de colaboración en el desarrollo de sus programas de energía nuclear con fines civiles, las cuales se convierten sólo en algunas de las aristas de estos fenómenos referidas a lo largo del trabajo.

Considerando lo hasta aquí expuesto, pretendemos avanzar en la exploración del devenir de estos lazos atendiendo a diversas fuentes secundarias -principalmente artículos de prensa nacional e internacional-, pero también primarias -declaraciones oficiales, comunicados de prensa e informes estadísticos-.

Finalmente, es importante aclarar que el trabajo se estructura en torno a tres apartados en los que se abordan las distintas dimensiones de la política exterior. El primero versa sobre la evolución de los vínculos político- 
diplomáticos, el segundo sobre el devenir de las relaciones económicos-comerciales y el tercero sobre los incipientes lazos estratégico-militares entre los socios del MERCOSUR y sus pares del CCG.

\section{La profundización de las relaciones político-diplomáticas}

Tal como se expuso en la introducción del trabajo, si bien los vínculos entre los miembros originarios del MERCOSUR y sus pares del CCG históricamente se han caracterizado por su baja densidad, los mismos comienzan a profundizarse paulatinamente, a partir de la I Cumbre ASPA.

En lo que respecta a la génesis de estos encuentros es necesario contextualizar sus orígenes en la búsqueda del presidente brasileño, Lula Da Silva (2003-2010), de impulsar nuevos vínculos económicos-comerciales y fortalecer el posicionamiento de su país a nivel internacional.

En este sentido, Soares Da Lima (2005) define la estrategia de inserción internacional adoptada por dicho gobierno como autonomista; siendo esta una estrategia que combina "el objetivo de proyección internacional" con la "permanencia del mayor grado de flexibilidad y libertad de la política externa". Asimismo, la autora agrega que esta propuesta preconiza una política activa de desarrollo que debe buscarse en conjunto con otros países con intereses semejantes.

En esta misma línea, otra de las particularidades de la política de inserción internacional de Lula fue la diversificación de los socios, principalmente entre los países del sur. Al punto de que hay quienes definen esta política como "autonomía por la diversificación" (Vigevani, Capeluni, 2007). De hecho, por medio de la diversificación de las relaciones externas se apuntó no sólo a obtener nuevos socios comerciales sino también a ganar apoyos para la construcción de un orden internacional más justo y equitativo donde los países en desarrollo tuviesen voz y espacio y en el cual Brasil pudiese ocupar un lugar protagónico. Así la cooperación sur-sur ganó fuerza tanto a través de la búsqueda de alianzas con los grandes países en desarrollo como con otros países en desarrollo, pero en este caso más pobres (Figueiredo, Riediger, 2014).

En pos de un mayor protagonismo internacional, la participación en distintos foros, la diversificación de los socios comerciales y la presencia en diversas regiones del mundo resultó esencial.

En este marco se inscribe la gira de Lula por Medio Oriente, en 2003, que el presidente aprovechó para presentar la idea de organizar una Cumbre que convocase a los Estados de América del Sur y los países miembros de la Liga Árabe. 
Como correlato de su iniciativa, en mayo de 2005 tomó lugar en Brasilia la primera Cumbre de Jefes de Estado y de Gobierno América del Sur - Países Árabes. Así surge el ASPA como un mecanismo de cooperación biregional que en términos políticos apuesta a profundizar el diálogo interregional, concertar sobre los principales temas de orden regional e internacional y ampliar la cooperación en el marco de los foros multilaterales y entre las organizaciones regionales. A nivel económico, pretende consolidar la cooperación sur-sur a través de mayores intercambios comerciales, de turismo e inversión. En tanto, en el terreno cultural busca promover la divulgación de patrimonio árabe en los países de América del Sur y viceversa (Vagni, 2009).

Tras la primera cumbre ASPA, en 2005, se han sucedido tres encuentros; la segunda cumbre ASPA tuvo lugar en Doha en 2009, la tercera se desarrolló en Lima en 2013 y la cuarta se organizó en Riad en 2015. Paralelamente, múltiples reuniones a nivel ministerial han favorecido un acercamiento entre los actores que conforman ambas regiones. Al respecto, se busca prestar atención a la aproximación entre los países miembros del CCG y los socios originarios del MERCOSUR que ha cobrado impulso desde 2005 para profundizarse durante el último lustro.

Dicho esto, en lo que atañe a los vínculos político-diplomáticos entre los citados actores, sin pretender ser exhaustivos, puede mencionarse que durante el primer gobierno del PT (2003-2007), en 2005, el canciller Celso Amorim visitó Arabia Saudita, Kuwait, Qatar y Omán con motivo de la preparación de la I Cumbre ASPA. A posteriori, en 2008, el ministro de Relaciones Exteriores brasileño volvió a visitar Qatar y Arabia Saudita. En tanto, durante su segundo mandato el presidente Lula Da Silva (2007-2010) arribó a Doha, en 2009, en el marco de su participación en la II Cumbre ASPA. Asimismo, a lo largo de dicho año también protagonizó una visita oficial a Arabia Saudita; mientras que Brasilia recibió la visita del canciller de EAU. En 2010 el presidente brasileño, una vez más, desembarcó en Qatar. Además, ese año arribaron al país el primer ministro de Kuwait y el emir y el primer ministro de Qatar, mientras que el canciller brasileño viajó a Doha. Tras la asunción de Rouseff en 2011, en 2012 arribaron al país el canciller de EAU y su par qatarí. Un año después el vice presidente de Brasil desembarcaba en EAU y Omán. Luego, la presidente visitó Qatar en 2014. Asimismo, ese año recibió la visita del primer ministro y vicepresidente de los EAU. Es más, es importante señalar que los contactos hasta aquí referidos se corresponden sólo con aquellos del más alto nivel. De hecho, en este párrafo no se ha profundizado en las visitas a nivel ministerial efectuadas y recibidas, que han sido numerosas.

En cuanto a la Argentina, durante el gobierno de Néstor Kirchner (2003-2007) se produjo una gira del vicecanciller argentino por Arabia Saudita, Emiratos Árabes y Kuwait en 2005, a pocos meses de concluida la I Cumbre ASPA. Mientras que en 2007 arribaron a la Argentina el presidente del parlamento de Arabia Saudita y un grupo de parlamentarios kuwaitíes. De cualquier forma, es recién durante las gestiones de Fernández (2007-2015) que se registra un fuerte incremento de los contactos al más alto nivel entre Buenos Aires y los países del CCG. En efecto, durante sus gobiernos se multiplicaron los viajes presidenciales, las visitas ministeriales y contactos de alto nivel con 
representantes de los citados países e, incluso, se avanzó en la apertura de nuevas sedes diplomáticas. En 2009 Buenos Aires recibió la visita del ministro de Relaciones Exteriores de EAU, en 2010 del emir y el primer ministro de Qatar, así como también del primer ministro de Kuwait. Por otra parte, en 2011, la presidente Fernández efectuó una gira que tuvo por destino a Kuwait y Qatar. En cuanto al segundo gobierno de Fernández, en 2012, el vicepresidente se dirigió a Qatar para participar del XIII Foro de Doha sobre temas relacionados con la democracia, el desarrollo social y el libre comercio en Medio Oriente. Asimismo, en 2013, Fernández protagonizó la primera visita de un jefe de Estado argentino a EAU, un gesto de alto impacto político que fue retribuido con la visita a Buenos Aires del vicepresidente de Emiratos al año siguiente. Luego, en 2014, el canciller argentino arribó a Dubai donde fue recibido por el vicepresidente y primer ministro de EAU en otra reunión que expone la importancia que no sólo Argentina sino también Emiratos le asignó a la profundización del vínculo bilateral.

En el caso del Paraguay los contactos también se han intensificado en el último lustro. De hecho, en 2010, Asunción recibió la visita del Emir de Qatar. En tanto, en 2014, el ministro de Relaciones Exteriores de EUA visitó el país. A posteriori, en 2015, los ministros de Economía y de Industria y Comercio de Paraguay visitaron Qatar en lo que fue la primera visita de su tipo al Emirato.

En lo que atañe a Uruguay, en 2007 el presidente Tabaré Vázquez (2005-2010) realizó una gira que lo llevó a Emiratos Árabes y Qatar y que, conforme con declaraciones oficiales tuvo por fin "abrir nuevos mercados y atraer inversiones" desde países "notoriamente ricos y poderosos a partir del lugar que ocupan en el concierto de las naciones productoras de petróleo" (Cotelo, 2007). Mientras que, en 2010, Montevideo recibió la visita del Emir de Qatar. Un año después arribaba al país el primer ministro de Kuwait. En 2013 sería el turno del príncipe de Arabia Saudita Abdul-Aziz bin Talal bin Abdul-Aziz Al Saud. Luego, en 2014, se recibió la visita del ministro de Relaciones Exteriores de EAU. Finalmente, en 2015, el canciller uruguayo visitó Qatar y Arabia Saudita, y Montevideo recibió una nueva visita del ministro de Relaciones Exteriores de EAU.

También en esta dirección, y en línea con el fortalecimiento de los lazos entre los referidos actores, podemos mencionar que Qatar abrió su embajada en Brasil en 2007 y Omán hizo lo propio en 2010. Por otra parte, en 2008 EAU abrió su embajada en Buenos Aires. Mientras que, en el marco de la visita de Fernández a Qatar, en 2011, se asumió el compromiso de abrir la embajada argentina en Qatar y la qatarí en Buenos Aires, lo que finalmente se concretó en 2013, cuando ambos Estados designaron sus primeros embajadores. De esta forma, en la actualidad Argentina cuenta con embajadas en cuatro de las seis monarquías del Golfo, puesto que en los casos de Omán y Bahrein existe una representación concurrente en el reino saudita. 
Tabla I: Apertura de embajadas por parte de los socios del CCG.

\begin{tabular}{|c|c|c|c|c|}
\hline & Argentina & Brasil & Paraguay & Uruguay \\
\hline Arabia Saudita & 1977 & 1973 & & \\
\cline { 1 - 3 } Bahrein & \multicolumn{3}{|c|}{} \\
\cline { 1 - 3 } EAU & 2008 & 1991 \\
\hline Kuwait & 1993 & 1975 \\
\hline Oman & & 2010 & & \\
\hline Qatar & 2013 & 2007 & & 2011 \\
\hline
\end{tabular}

Fuente: Elaboración propia sobre la base de información recabada de las páginas oficiales de los respectivos gobiernos.

Por su parte, Paraguay sólo cuenta con una embajada en Qatar que abrió sus puertas en 2015. En tanto ninguno de los miembros del CCG ha abierto una representación del más alto nivel en dicho país. Distinto es el caso de Uruguay, que abrió su embajada en Doha en 2008 y en Abu Dhabi en 2014. Por su parte, Qatar es el único país del bloque árabe que cuenta con una embajada en Montevideo, instalada en 2011.

Tabla II: Apertura de embajadas por parte de los socios del MERCOSUR.

\begin{tabular}{|l|c|c|c|c|c|c|}
\hline & Arabia Saudita & Bahrein & EAU & Kuwait & Omán & Qatar \\
\hline Argentina & 1964 & & 1983 & 1993 & & 2013 \\
\hline Brasil & 1973 & & 1978 & 1975 & 2008 & 2005 \\
\hline Paraguay & & & & & & 2015 \\
\hline Uruguay & N/D & & 2014 & & & 2008 \\
\hline
\end{tabular}

Fuente: Elaboración propia sobre la base de información recabada de las páginas oficiales de los respectivos gobiernos.

N/D: Dato no disponible

Otro indicador del referido acercamiento entre las partes, si bien de menor peso, reside en la llegada de Qatar Airways, Emirates Airlines y Etihad Airways a la región. En efecto, desde 2010 Qatar Airways vuela la ruta DohaBuenos Aires y, desde 2011, Emirates Airlines cubre el trayecto entre Dubai y Buenos Aires, en ambos casos con escala en Brasil que, por su parte, cuenta con vuelos directos hacia ambos destinos incluso con anterioridad a la apertura de estas rutas en la Argentina. En tanto, Etihad Airways enlaza Abu Dhabi y San Pablo desde 2013 y, en 2014, firmó un acuerdo de código compartido con Aerolíneas Argentinas.

De los datos hasta aquí expuestos llama la atención la ofensiva diplomática desplegada por EUA y Qatar que en los últimos años han demostrado interés en acercarse a la región, tal como se evidencia a partir de las visitas efectuadas, la apertura de representaciones diplomáticas y el establecimiento de rutas aéreas. Un vínculo que, por 
otra parte, los socios del MERCOSUR también han apostado a cimentar. Particularmente atendiendo a los enormes recursos que manejan ambos actores del Golfo.

Al respecto, EAU se presenta como el séptimo país del mundo por el tamaño de sus reservas de crudo, 97.800 millones de barriles, y el octavo productor mundial de petróleo (CIA, 2015). Además, cuenta con importantes reservas de gas que rondan los 215.000 millones de pies cúbicos (Oficina Económica y Comercial de España en Riad, 2015). No obstante, vale mencionar que, en la última década, este país ha efectuado importantes avances en términos de diversificación económica. Tal es así que este Estado se ha transformado en un importante centro económico, comercial y financiero. Asimismo, en un hub logístico y centro de reexportaciones, no sólo para la región del Golfo sino también para países del norte de África, y las ex repúblicas soviéticas. Esto sin mencionar que el fondo soberano de EAU es uno de los más importantes a nivel internacional al contar con activos por U\$\$ 773.000 millones (Sovereign Wealth Funds Institute, 2015).

En tanto, Qatar posee uno de los PBI per cápita más altos del mundo. Tal como ocurre en el caso de sus socios del CCG, sus ingresos derivan principalmente de las exportaciones de hidrocarburos. En efecto, este país es el primer productor de gas licuado del mundo y posee el 14\% de las reservas de gas a nivel global (Gulf Exporting Country Forum, 2015). Actualmente su fondo soberano cuenta con U\$\$ 256.000 millones (Sovereign Wealth Funds Institute, 2015).

Por otra parte, en términos comparativos con el resto de las monarquías del Golfo, las relaciones entre los miembros del MERCOSUR y Riad tienen una trayectoria más extensa. En efecto, el reino se encontró entre los primeros países árabes con los cuales Argentina estableció relaciones diplomáticas, que en este caso datan de 1946. Es más, Buenos Aires abrió su primera legación diplomática en el Golfo en la ciudad de Yeda en 1948, convirtiéndose en el primer Estado latinoamericano en tener una representación diplomática en el país. Por su parte, las relaciones diplomáticas entre el reino y Brasil datan de 1968. Ahora bien, la naturaleza de los vínculos vigentes con Arabia Saudita se explica en función del lugar que este país ocupa dentro del escenario de Medio Oriente, no sólo por sus importantísimas reservas de hidrocarburos - al ser el segundo país con las mayores reservas probadas de crudo del mundo, con aproximadamente 268 millones de barriles (CIA, 2015)- sino también por ser el custodio de los lugares sagrados del Islam. En efecto, el reino se destaca no sólo por la importancia de sus recursos hidrocarburíferos sino también por su peso político, siendo uno de los actores que a través del tiempo ha competido por el liderazgo regional.

Ahora bien, cabe mencionar que el impulso que han ganado los vínculos con EUA, Qatar, Arabia Saudita y Kuwait, estos últimos también con una trayectoria más extensa, no tiene su correlato en lo que atañe a las relaciones con Omán y Bahrein. De hecho, Bahrein no cuenta con representaciones diplomáticas al más alto nivel en ninguno de 
los países miembros del MERCOSUR y Omán sólo ha abierto una embajada en Brasil. Como contrapartida, a excepción de Brasil que cuenta con una embajada en Omán desde 2008, el resto de los países miembros del bloque sudamericano tampoco han abierto embajadas en dichos Estados. Es más, los contactos mantenidos a nivel político con estos actores tampoco han tenido la asiduidad y la profundidad de los vínculos sostenidos con los demás miembros del CCG. No obstante, las relaciones entre Brasil y Omán han comenzado a profundizarse desde 2008 proliferando las visitas a nivel ministerial ${ }^{2}$.

En lo que atañe a las relaciones con Bahrein, Paraguay recién estableció relaciones diplomáticas con dicho país en 2005 ( $A B C, 2005)$. Aun más, no se ha podido recabar datos que den cuenta de visitas oficiales del más alto nivel ya sea desde Bahrein hacia alguno de los países miembros del MERCOSUR o viceversa durante este período. Incluso llama la atención que, si bien en 2011 el príncipe heredero de Bahrein visitó la provincia argentina de Santiago del Estero, acompañado de una comitiva de inversores y empresarios (Sitio oficial de la Provincia de Santiago del Estero, 2011), no haya sido recibido por altas autoridades del gobierno nacional.

\section{El devenir de los vínculos económico-comerciales}

Considerando las características de los países del Golfo previamente referidas, se evidencia que la búsqueda de nuevos socios ha sido un factor central que ha impulsado el acercamiento de los países miembros del MERCOSUR a sus pares del CCG. Particularmente, si se tiene en cuenta la complementariedad de las economías de estos Estados, y las potencialidades del comercio entre este conjunto de actores que resultan de la necesidad de alimentos y materias primas por parte de los países del Golfo, que los miembros del MERCOSUR están en condiciones de satisfacer, y del amplio poder adquisitivo de los citados países árabes y la búsqueda de atraer inversiones por parte de los países sudamericanos.

En efecto, estos factores impulsaron que en el marco de la I Cumbre ASPA, en 2005, se arribase a la firma de un Acuerdo Marco de Cooperación Económica entre el MERCOSUR y el CCG, que apunta a promover la cooperación en materia económica, comercial, técnica y de inversión y crea un Comité Conjunto con el legado de trabajar en pos de la conclusión de un Acuerdo de Libre Comercio.

\footnotetext{
${ }^{2}$ En 2008 visitaron Brasil los ministros omaníes de Industria y Comercio, y Economía. Luego, en 2012, lo hicieron sus pares de las carteras de Medio Ambiente y Desarrollo Social. Como contrapartida, en 2013 visitó Omán el vice-presidente de Brasil, en el marco de cuya visita se firmaron los dos primeros acuerdos bilaterales entre estos dos países; a su vez, llegó a Brasilia el ministro de Educación del sultanato. Información disponible en la página oficial del Ministerio de Relaciones Exteriores de Brasil:

http://www.itamaraty.gov.br/index.php?option=com_content\&view=article\&id=5615\&ltemid=478\&cod_pais=OMN\&tipo=ficha_pais\&lang=ptBR
} 
En línea con lo hasta aquí expuesto, el canciller de Brasil, Celso Amorim, destacaba: "Es un acuerdo de gran importancia histórica. El Consejo reúne países de altos ingresos per cápita". A lo que agregaba que un acuerdo con estos países "crea oportunidades nuevas de comercio y detrás del comercio van las inversiones" (Cronista, 2005).

Respecto al avance de las negociaciones, es menester señalar que en 2007 representantes de ambos bloques firmaron una declaración conjunta en la que se da cuenta que el acuerdo "es una de las prioridades en la agenda de negociación de cada región, considerando su relevancia global, la dimensión de las economías de ambos bloques y las oportunidades concretas de negocios por abrirse". Aún más, en dicha oportunidad se dio a conocer que las partes habían avanzado sobre un 90\% del texto (Rocha, 2007).

Conforme con la mentada declaración, los tramos del acuerdo que estaban prácticamente completos eran: el texto de apertura y los puntos generales del acuerdo, el capítulo sobre el comercio de mercancías, el capítulo sobre servicios, el capítulo de inversiones, las disposiciones institucionales y las declaraciones finales. Aún más, en dicho documento se preveía la finalización de las negociaciones para junio de 2007; sin embargo, al día de hoy eso no ha ocurrido. Por el contrario, con el correr del tiempo las mismas se han ralentizado. Esto esencialmente como correlato de las dificultades que las partes han encontrado para liberalizar el comercio de productos petroquímicos. Pues, considerando que entre los miembros del CCG se encuentran algunos de los países con mayores reservas de hidrocarburos a nivel internacional, los miembros del MERCOSUR han mostrado reparos a la hora de abordar la apertura de dicho sector (Rocha, 2007).

Ahora bien, a pesar de no haberse logrado concluir las negociaciones por la firma del acuerdo de libre comercio, el acercamiento entre estos actores se profundizó tras las crisis de 2008. En efecto, tras el desencadenamiento de la referida crisis, que afectó particularmente a los países desarrollados -entre ellos a algunas de las economías más grandes del mundo- estos tendieron a reaccionar con una profundización de las políticas proteccionistas. En este marco los países miembros del MERCOSUR pusieron especial ahínco en la diversificación de mercados, aproximándose a los países del Gofo que son percibidos como socios potenciales.

Tal es así que el entonces secretario de Relaciones Comerciales Internacionales de la Argentina, Luis María Kreckler, en el marco de una gira por el Golfo que tuvo lugar en 2011 mencionaba: "A partir de la crisis financiera se volvió indispensable diversificar los mercados, éste es uno de esos mercados a los que se debe apuntar [en referencia a los países del Golfo]. Lo mismo que hacemos con los países que integran el BRIC (Brasil, Rusia, India y China) y otros mercados en vías de desarrollo" (Cibeira, 2011).

En esta misma dirección, el canciller argentino Timerman señalaba: “El crecimiento de nuestras ventas al mundo reconoce como uno de sus pilares a la estrategia de diversificación de nuestra oferta exportable y a una 
política comercial que prioriza la apertura de nuevos mercados para las exportaciones argentinas, logrando posicionar la producción nacional en mercados menos tradicionales como África - particularmente la región del Magreb-, Medio Oriente, la India y el Sudeste Asiático, entre otros" (Secretaría de Comunicación Pública, 2011). En tanto, un comunicado de prensa de la Cancillería Argentina, del 14 de febrero de 2014, subraya que las monarquías del Golfo constituyen destinos estratégicos por numerosas razones.

Entre ellas, su papel protagónico en los mercados de gas y petróleo y sus elevados superávits de cuenta corriente que les permiten acumular excedentes para destinar a consumo e inversión. De los tres destinos mencionados, Arabia Saudita es la economía de mayor tamaño. Al igual que nuestro país, es miembro del G20, foro en el cual tenemos posiciones afines respecto de diversos temas de la agenda internacional. Además del potencial de la relación bilateral, Arabia Saudita constituye un importante socio comercial de nuestro país, dado que en 2013 se sumó a lista de destinos a los cuales exportamos más de 1.000 millones de dólares anuales. Qatar posee la tercera reserva mundial de gas y es el mayor exportador mundial de gas licuado. Debido a esto resulta de interés promover la cooperación en las tecnologías para el uso del GNC. En este campo, existen oportunidades para que ambos países puedan beneficiarse del desarrollo tecnológico y la experiencia acumulada, sea comercialmente o a través de inversiones. Emiratos Árabes Unidos posee uno de los ingresos per cápita más altos en la región y es un hub desde el cual se reexportan productos, desde todo el mundo, a Asia y Medio Oriente. (Ministerio de Relaciones Exteriores y Culto, Información de Prensa $N^{\circ}$ 028/14).

Por su parte, en el marco de un encuentro con representantes del gobierno saudí, el presidente uruguayo, José Mujica (2010-2015) mencionaba: "Nuestra política debe ser vender al mayor número de mercados como sea posible y no concentrarnos en uno o dos grandes compradores" (United Press International, 2010). Y en otra ocasión agrega: "Consideramos que es inteligente procurar vender en aquellos mercados que tienen mayor posibilidad de pago y que, en alguna medida, tienen necesidades estratégicas de lo que nosotros producimos" (Presidencia de la República Oriental del Uruguay, 2010). Aún más, teniendo en consideración los factores que motivan el acercamiento de los miembros del CCG a los socios del MERCOSUR, el Ministro de Agricultura de Uruguay señaló "Sabemos que estos países están con esta estrategia de venir a invertir en recursos naturales y lo que les propusimos... [es que si lo que necesitan] es seguridad alimentaria entonces el Uruguay es un país con larga trayectoria agroexportadora" (Presidencia de la República Oriental del Uruguay, 2010).

Considerando lo hasta aquí expuesto, es importante destacar que entre 2001 y 2012 el comercio entre el MERCOSUR y el CCG presentó una tasa de crecimiento del 17\%. Mientras que, para 2012, el volumen de comercio interbloque ascendió a U\$\$ 15.000 millones, con un saldo favorable al primero que giró en torno a U\$\$ 3.000 millones (Bartesaghi, Mangana, 2014). 
Dicho esto, cabe mencionar que quien tracciona el comercio del MERCOSUR para con los socios del CCG es Brasil, que en 2012 fue responsable del 86\% de las exportaciones y el 89\% de las importaciones desde ese origen. Mientras que en importancia le sigue Argentina con el $13 \%$ de las exportaciones y el $10 \%$ de las importaciones. En tanto, los restantes miembros del bloque tienen escasa participación en el comercio con los países del Golfo (Bartesaghi, Mangana, 2014).

Los principales socios comerciales de Brasil en el Golfo, en 2012, fueron Arabia Saudita, hacia donde se exportó por U\$ 3.000.113.126 FOB, y EAU con ventas por U\$ 2.456.755.780 FOB. En tanto el país que presentó el mayor total importado fue Arabia Saudita con importaciones por U\$\$ 3.196.828.700 FOB, seguido muy por detrás por Qatar con importaciones por U\$ 748.358.169 FOB (Ministerio de Desenvolvimiento, 2015).

Respecto a la Argentina, Arabia Saudita también se presentó como el primer destino de exportación entre las monarquías del Golfo. En 2012 Argentina exportó a Riad por U\$\$ 816.487.000 FOB, mientras en término de relevancia una vez más le siguió EAU, a donde se exportó por U\$\$ 306.640.000 FOB (Cámara de Comercio Argentino Árabe, 2015). En tanto, en 2012, Qatar se convirtió en el país de la región desde el cual Argentina más importó, con un total importado de U\$ 448.592.000 CIF, seguido muy por detrás por Arabia Saudita, con quien se registra un saldo total importado de U\$\$ 75.290.000 CIF (Cámara de Comercio Argentino Árabe, 2015).

En torno a la composición de las ventas, entre las exportaciones se destacan las materias primas y los alimentos, entre ellos, carne vacuna y aviar, cereales, oleaginosas, aceites y azúcar. Como contrapartida las importaciones del MERCOSUR se encuentran fuertemente concentradas en torno a los combustibles minerales. Tal es así que en 2012 el 88\% de las importaciones del bloque se correspondieron con los mismos, seguidos en orden de relevancia por los abonos, los plásticos y sus manufacturas y los productos químicos, entre otros (Bartesaghi, Mangana, 2014).

Vale agregar que, si bien las exportaciones e importaciones de Uruguay y Paraguay hacia y desde estos destinos resultan sobradamente más acotadas que aquellas de los dos grandes socios del MERCOSUR, estos países han buscado capitalizar el interés de los actores del Golfo en los recursos y las oportunidades que presenta la región. En esta línea diversos indicadores exponen la voluntad de estos actores de trabajar en pos de una profundización de los vínculos económico-comerciales con los miembros del CCG. Entre ellos: las visitas de alto nivel, las misiones comerciales, la participación en ferias internacionales que toman lugar en la región, incluso la apertura de representaciones diplomáticas que, sin lugar a dudas, también colaboran al estrechamiento de lazos entre las partes.

Respecto de los vínculos con la región, el Embajador de Paraguay en Qatar menciona "Esperemos que, con nuestro trabajo, nuestro esfuerzo, [...] se abran las puertas definitivamente y esto pueda significar realmente un 
desarrollo y un polo de venta de nuestros productos, del campo principalmente, me refiero a arroz, soja, trigo, agua, carne, pollo" (Presidencia de la República del Paraguay, 2015).

En línea con las declaraciones del embajador y considerando las características que presentan el suelo y el clima en los países miembros del CCG, sumado al crecimiento de la población que se espera en los mismos, se hace evidente que existen grandes posibilidades de incrementar las ventas por parte de los socios sudamericanos, tanto de materias primas como de alimentos procesados, hacia los países del Golfo. De hecho, amplias porciones del territorio de estos estados son desérticas, a lo que se suman temperaturas que en verano superan los $45^{\circ}$. Esto sin mencionar la escasez de agua que es otro factor que limita los cultivos en aquellas latitudes, siendo particularmente preocupantes

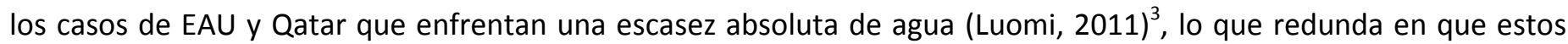
seis Estados deban comprar prácticamente la totalidad de los alimentos que consumen.

Sobre la base de lo hasta aquí expuesto y atendiendo a que la proyección de la necesidad de alimentos por parte de este conjunto de países es cada día mayor, los miembros del CCG se han acercado a los Estados sudamericanos en gran medida con el objetivo de garantizar su seguridad alimentaria. En esta línea, Shiloh (2012) menciona que los Estados del Golfo han enfrentado el desafío que presenta la seguridad alimentaria desde un enfoque sistemático que excede la importación de alimentos e incluso la creación de enormes reservas de productos alimenticios. Para luego señalar que estos países se han esforzado por mejorar las relaciones con docenas de países de todo el mundo que tienen grandes extensiones de tierras fértiles, entre los que se encuentran los países del MERCOSUR.

En este marco, en el último lustro, Buenos Aires ha recibido delegaciones provenientes de las monarquías del Golfo que llegaron al país para avanzar en la firma de acuerdos de joint venture con contrapartes argentinas. Estos acuerdos prevén que la parte árabe aporte el capital para la siembra, para luego poder disponer de parte de la producción. Por otro lado, también se ha dado a conocer que empresas procedentes de Arabia Saudita han procedido a comprar tierras que luego serían destinadas a la actividad agrícola en Argentina. Tal es así que, tras la decisión del gobierno del reino de eliminar el uso de agua para producir cultivos intensivos, en 2011 la corporación saudita Almarai compró Fondomonte S.A., una compañía que contaba con alrededor de 12.000 hectáreas para el cultivo en la Argentina, lo que le permitió a la primera pasar a contar con casi 30.000 hectáreas de tierra cultivable en el país (Radic, 2012). Por otra parte, también existe información que da cuenta de que el gobierno de Qatar inició conversaciones con Argentina para comprar tierras agrícolas que serían dedicadas a la producción de cereales en lo que fue valuado como un acuerdo de más de U\$\$ 100 millones (Eleisegui, 2010). Lo cierto es que, desde 2011, la compra de tierras en dicho país se ha visto restringida a partir de la adopción de una ley que prácticamente prohíbe la

\footnotetext{
${ }^{3}$ Afrontan escasez absoluta de agua aquellos países que disponen de menos de $500 \mathrm{~m} 3$ de agua fresca renovable por persona por año.
} 
adquisición de parcelas por parte de extranjeros (Radic, 2012). Algo similar ocurre en Brasil donde, pese al interés de los países árabes, también se ha limitado la compra de tierras por parte de capitales extranjeros (Radic, 2012).

Ahora bien, vale insistir en que detrás de estos intentos de corporaciones de Medio Oriente, ya sea por avanzar en la firma de acuerdos de joint ventures o por hacerse de tierras productivas, se encuentra la preocupación de estos países por su seguridad alimentaria, así como también por acceder a reservas de agua virtual.

En otro orden, se evidencia que el flujo de capitales ha sido un objetivo fuertemente perseguido por los países del MERCOSUR y, en su beneficio, un componente importante del acercamiento de las monarquías del Golfo a dichos Estados. En este sentido, Brasil se presenta como el país de Sudamérica que ha recibido mayores inversiones provenientes de los países del CCG.

Sólo por citar algunos ejemplos, en 2010 Abu Dhabi Investment Authority adquirió un edificio de oficinas en Río de Janeiro por US\$ 300 millones. Además, a finales de ese mismo año dicho fondo, junto a otros ocho, entró con una inversión total de US\$1.800 millones al banco de inversiones BTG Pactual (Radic, 2012). Esto sin mencionar que este fondo posee participaciones en la Bolsa de São Paulo y bonos brasileños (Santiso, 2011). Mientras que, en 2012, Mubdala, fondo perteneciente exclusivamente al gobierno de Abu Dhabi, colocó USD 2.000 millones para estimular las inversiones de EBX, una compañía afincada en petróleo, gas, minería, puertos y electricidad, entre otros (Radic, 2012). En tanto, en 2010, la Qatar Investment Authority invirtió USD 2.153 millones en la compra del 5\% del Santander Brasil, filial en la que también se interesó el fondo Aabar Investments, de capitales emiratíes (Rebossio, 2012).

En la Argentina, EAU posee inversiones en terminales portuarias y cadenas hoteleras. Sin ir más lejos, Dubai Port World, uno de los principales operadores portuarios del mundo, comprometió una inversión de USD 300 millones que se volcaron en obras de infraestructura y tuvieron por fin una modernización del Puerto de Buenos Aires (Cronista, 2012). En tanto, Kuwait y Qatar declararon a Argentina "destino estratégico de inversión” (Cibeira, 2011), una decisión que se espera allane el camino a la llegada de capitales. Un dato interesante a mencionar reside en que, si bien hasta el momento Argentina no ha recibido fondos provenientes de la Autoridad de Inversión de Kuwait, sí ha receptado un préstamo del Fondo Kuwaití para el Desarrollo Económico Árabe. De hecho, este fondo, pensado originalmente para el desarrollo de los países árabes, hace tiempo se ha abierto hacia otros destinos emergentes, principalmente en América Latina. En este marco, la Provincia de Santa Fe fue destinataria de un préstamo para mejorar su red ferroviaria (Cibeira, 2011). En esta misma línea, el empresario saudí Alí Albwardy invirtió USD 23 millones en remodelar el hotel Four Seasons en Buenos Aires y el grupo Al-Khorayef, del mismo país, apostó USD 356 millones en un proyecto agrícola en la selva de El Impenetrable, en la provincia del Chaco (Rebossio, 2012). 
Básicamente se apostó a reconvertir 300.000 hectáreas, a mejorar las tierras, con el fin último de favorecer los cultivos, para lo cual se procedió a un desembolso de USD 400 millones (Eleisegui, 2011).

En lo que atañe a Uruguay, en 2014 se dio a conocer que dicho país negociaba con EAU una inversión de USD 1.000 millones para la construcción de un puerto de aguas profundas en Rocha, a raíz de la experiencia emiratí en proyectos portuarios en Perú, República Dominicana y Brasil (Cpampa, 2014). No obstante, no ha podido recabarse información que dé cuenta de la concreción de un acuerdo entre las partes.

Finalmente, como contrapartida al flujo de capitales árabes que tuvieron por destino a los dos grandes socios del MERCOSUR, puede mencionarse que se han abierto oficinas de los bancos Itaú y do Brasil, del mismo país, en Dubai. Por otro lado, la minera brasileña Vale instaló un complejo industrial en Omán que cuenta con dos plantas de peletización y un centro de distribución ubicado en un puerto de aguas profundas en la localidad de Sohar (Góes, 2012).

\section{Los incipientes lazos estratégico-militares}

Amén de la profundización de los lazos político-diplomáticos y económico-comerciales entre los socios del MERCOSUR y sus pares del CCG, también podemos dar cuenta de ciertos avances en lo que atañe a la cooperación en materia estratégico-militar entre algunos de los miembros de estos dos bloques que han tenido lugar en los últimos años. En esta línea, Brasil y Argentina han logrado concretar acuerdos y avanzar en negociaciones en materia de defensa, en el terreno nuclear y satelital con EAU, Arabia Saudita y Qatar.

Sin ir más lejos, durante la visita del primer ministro de EAU a Brasil, en 2014, los representantes de ambos gobiernos firmaron un acuerdo que prevé la cooperación entre las industrias de defensa de sus respectivos países, el intercambio de tecnología, así como también de información militar. Además, este documento habilita el gerenciamiento conjunto de crisis, y abre la puerta a la cooperación en lo referente al entrenamiento militar y al intercambio de armamento, equipamiento y servicios de defensa (Interdefensa, 2014).

En esta misma dirección, a principios de 2015, el gobierno brasileño dio a conocer que EUA estaba interesado en adquirir de Embraer Defensa \& Seguranca veinticuatro A-29 Super Tucanos que serían empleados en misiones de entrenamiento y ataques leves. De estos aviones seis fueron requeridos de forma urgente para ser utilizados en el entrenamiento de pilotos de la fuerza aérea de EAU (Infodefensa, 2015).

En lo que hace al acercamiento de Argentina a sus contrapartes del Golfo, en el terreno estratégico debemos mencionar que, si bien dicho país no ha firmado acuerdos de defensa, tal como ha sido el caso de Brasil, sí se ha 
volcado a impulsar la cooperación en el ámbito nuclear con los socios del CCG. De hecho, Argentina no sólo es uno de los pocos países en desarrollo que ha logrado avances sustanciales en el campo nuclear, sino que fue el primer país en Latinoamérica en instalar una central nuclear transformándose, con el correr del tiempo, en exportador de sus innovaciones en esta materia.

Por su parte algunos de los socios del CCG han demostrado su interés en el desarrollo nuclear movidos por factores varios. Ante todo, cabe recordar que estos países cuentan con vastas reservas de hidrocarburos. Sin ir más lejos, las seis monarquías del Golfo poseen alrededor del 30\% de las reservas probadas de crudo a nivel global. Aún más, estos seis Estados controlan conjuntamente el 23\% de las reservas probadas de gas a nivel mundial (Meltzer, Hultman, Langley, 2014). Como correlato, en estos países los hidrocarburos son responsables de un amplio porcentaje del PBI, de los ingresos por exportaciones y, asimismo, de la renta de los gobiernos (Bueno, Fabani, Fernández Alonso, 2011).

Ahora bien, el uso y abuso de los hidrocarburos que efectúan estas naciones ha implicado una fuerte dependencia económica de la explotación de estos recursos y ha desalentando la diversificación económica, en la cual sólo en los últimos años se viene trabajando. Esta dependencia ha ocasionado, asimismo, importantes consecuencias medioambientales.

Las monarquías del Golfo se ubican entre los países responsables de las mayores emisiones per cápita a nivel global (Banco Mundial, 2015), encontrándose el alto nivel de emisiones íntimamente vinculado con el volumen de extracción y la escala de producción de hidrocarburos. Asimismo, las altas emisiones per capita son fruto del amplio nivel de consumo de recursos que deriva en gran parte de la necesidad de generar energía para ser utilizada en refrigeración, en países que en verano deben afrontar temperaturas extremas, así como también del proceso de desalinización ante la escasez de reservas de agua dulce. Lo hasta aquí expuesto evidencia la necesidad que encuentran estos países de procurar un cambio en su mix energético.

Dejando de lado la problemática medioambiental, estos estados también han hecho manifiesto su interés de impulsar la energía nuclear movidos por un factor económico, la necesidad de bajar la factura energética y de reubicar recursos hidrocarburíferos que se consumen a nivel interno en el mercado externo.

Dicho esto, es importante señalar que Arabia Saudita ha sido el país del Golfo con el cual Argentina ha efectuado mayores avances en este ámbito. Tal es así que, en 2011, ambos Estados firmaron un acuerdo que apunta a la cooperación en el desarrollo y la utilización de la energía nuclear con fines pacíficos. Dicho documento introduce un marco legal que apuesta a impulsar la cooperación económica, científica y tecnológica entre las partes y aborda cuestiones tales como el diseño, la construcción y la operación de reactores comerciales y de investigación, la 
seguridad tecnológica nuclear, la seguridad física y la preparación de respuesta ante emergencias; el tratamiento y gestión de residuos; el uso de la tecnología nuclear para industria, medicina y agricultura y el entrenamiento y desarrollo de recursos humanos.

Vale mencionar que los diversos encuentros, reuniones, visitas, así como también los acuerdos firmados con representantes de aquel país, dieron por resultado la conformación de una empresa mixta integrada por la sociedad estatal INVAP y por su par saudí TACQNIA. Esta nueva entidad, denominada Invania, tiene por fin el desarrollo de tecnología, en especial nuclear, a partir de la experiencia argentina (Invap, 2015).

Aún más, como fruto de la labor conjunta, Argentina comenzó a realizar algunos trabajos para el reino saudí, esto en el marco de su búsqueda de abrirse caminos para exportar no sólo tecnología sino también servicios a los países del Golfo. De hecho, INVAP fue contratada para efectuar estudios, de forma tal de identificar el mejor lugar para instalar una planta de tratamiento del material radioactivo que surge de los pozos de petróleo y también para diseñar esa planta. Además, en los últimos años dicho país ha recibido estudiantes saudíes que se capacitaron en el Instituto Balseiro (Krakowiack, 2014).

En otro orden, durante la visita de Fernández a Abu Dhabi en 2013, los ministros de Relaciones Exteriores de ambos países firmaron un acuerdo para impulsar la cooperación en el desarrollo y la aplicación de la energía nuclear con fines pacíficos, constituyéndose este en el primer acuerdo de este tipo que Emiratos firmó con un país latinoamericano. Respecto al mismo, este prevé la transferencia de conocimientos, tecnología y material nuclear hacia Emiratos.

En esta misma dirección, en abril de 2014, en el marco de la visita del vicepresidente de EAU a Argentina, representantes de ambos gobiernos firmaron un memorando de cooperación, que tiene validez por cinco años. Este acuerdo prevé la cooperación en áreas tales como: educación y promoción de recursos humanos para el desarrollo seguro e integrado de la energía nuclear en EAU; gestión de residuos nucleares; seguridad tecnológica y participación en el proyecto nuclear civil de los Emiratos, entre otras. Además, establece que la cooperación podrá adoptar diversas formas: intercambio de información científica y técnica en el campo de los usos pacíficos de la energía nuclear; organización de seminarios técnicos, talleres y reuniones; capacitación de científicos y personal técnico; proyectos conjuntos; promoción de investigación y desarrollo conjunto y avanzado en el campo; asistencia en forma de soporte técnico de proyectos particulares o estudios desarrollados; intercambio de experiencias en operación y mantenimiento de instalaciones nucleares incluyendo la elaboración de guías de operación y mantenimiento. 
Como correlato del vínculo en esta área, hay quienes mencionan que la Argentina apunta a venderle el CAREM al Emirato, un reactor de diseño $100 \%$ argentino que podría servir para abastecer con energía a zonas aisladas, desalinizar agua de mar y realizar monitoreos ambientales (Krakowiak, 2014).

Finalmente, en lo que respecta a Qatar, los contactos entre Argentina y este país resultan más incipientes. De hecho, a diferencia de lo referido en relación con EAU y Arabia Saudita aún no se ha firmado ningún acuerdo en materia nuclear con este Estado. No obstante, es importante mencionar que sí han existido avances en la construcción de un vínculo con la Qatar Foundation, la entidad encargada de promover el desarrollo científico y tecnológico en el país. Al respecto, durante su visita a Qatar, en enero de 2011, Fernández se reunió con la sheikha Mozah Bint Nasser, quien dirige la citada organización, así como también con empresarios y referentes de fondos de inversión qataríes, en un encuentro en el que se dio a conocer el trabajo conjunto de la INVAP y la CNEA (Comisión Nacional de Energía Atómica) en materia de salinidad del agua y de desarrollo de centrales nucleares. Aún más, en dicha oportunidad la presidente invitó a un grupo de investigadores a visitar la Argentina con vistas a evaluar el desarrollo científico, tecnológico y nuclear del país. A posteriori, la profundización de los vínculos en materia nuclear también fue promovida por el canciller Timerman en el marco de una reunión con el ministro de Energía de Qatar que tuvo lugar como parte de su gira por la península arábiga, en febrero de 2014. Por último, hay fuentes que destacan que siendo el objetivo de Qatar convertirse en un polo internacional de desarrollo científico y tecnológico, Argentina le ha ofrecido venderle un reactor nuclear de investigación multipropósito (Krakowiack, 2014).

Por otro lado, la cooperación en materia satelital emerge como otra arista de la cooperación en terrenos estratégicos entre Argentina y EAU. En este sentido, también en el marco de la referida visita de Fernández a EAU en 2013, se alcanzó la firma de un memorándum de entendimiento entre la Comisión Nacional de Actividades Espaciales (CONAE) y la Institución Emiratí de Ciencia y Tecnología Avanzada (Emirates Institution for Advanced Science and Technology - EIAST). Este documento brinda el marco para que las partes puedan realizar proyectos espaciales conjuntos, proceder al intercambio de científicos y técnicos y de datos de sus respectivas misiones satelitales, avanzar en el desarrollo de programas industriales y comerciales y, asimismo, en la organización de seminarios y reuniones científicas conjuntas. De hecho, el acuerdo incluye un conjunto de iniciativas de cooperación entre las que se pueden citar: el desarrollo de aplicaciones de información satelital para la gestión y respuesta a las emergencias; la operación de estaciones satelitales terrenas y gestión de misiones satelitales; la organización de programas y facilidades para entrenamiento; el estudio de factibilidad de una alianza de estaciones terrenas para brindar cobertura global y servicios avanzados de segmento terreno (CONAE, 2013).

Tras la firma del citado documento, en julio de 2014, arribó a la Argentina una delegación del EIAST que mostró su interés en las instalaciones de ensayo y los laboratorios de la INVAP y la CONAE. Además, se ha dado a conocer que existen proyectos del segmento terreno de la Institución y de la Comisión para el apoyo de las misiones 
de satélites por las estaciones terrestres. Por otra parte, de acuerdo con declaraciones oficiales, existe la posibilidad de que se efectúen misiones internacionales conjuntas. No debe pasarse por alto que Argentina es el único país de América Latina que lanzó un satélite junto con la NASA, que entre sus usos sirve para el estudio las condiciones de los mares, su salinización, la pesca y la agricultura. En virtud de ello EAU puede descargar las imágenes de los satélites argentinos, lo que redunda en el intercambio de información y conocimientos entre ambos países (Malek, 2014).

\section{Reflexión final}

A través del tiempo los vínculos entre los socios originarios del MERCOSUR y sus pares del CCG han resultado acotados. No obstante, durante el gobierno de Lula Da Silva, en el marco de la búsqueda de Brasil de proyectarse internacionalmente e impulsar nuevos vínculos económico-comerciales, surge la iniciativa ASPA, favoreciendo un acercamiento entre las partes que se ha profundizado en el último lustro.

En efecto, desde 2005 en adelante han proliferado las visitas de alto nivel, encuentros y reuniones entre representantes de este conjunto de países e, incluso, han abierto sus puertas representaciones diplomáticas. Si bien es cierto que las relaciones entre estos actores han presentado divergencias en cuanto a su densidad, se han destacado aquellas de Brasil y Argentina para con sus contrapartes árabes.

En esta misma línea es posible mencionar que las relaciones político-diplomáticas, así como también aquellas económico-comerciales han tenido un desarrollo mayor que los vínculos estratégico-militares donde, sin embargo, Argentina apuesta a exportar tecnología y know how en materia nuclear.

Para culminar, entre los factores que explican el acercamiento entre las partes, además del impulso que brindan las cumbres ASPA, se destaca el desencadenamiento de la crisis financiera internacional que instó a los miembros del MERCOSUR a captar inversiones y a diversificar mercados, expandiendo el comercio con socios no tradicionales. Así como también la necesidad de las monarquías del Golfo de garantizar su seguridad alimentaria, ya sea a través de las importaciones de materias primas o por medio de la compra de tierras, y su búsqueda de efectuar avances en términos de cooperación tecnológica.

\section{Referencias bibliográficas}

ACUERDO BRASIL-EAU, Interdefensa, 29/04/2014. Disponible en:

http://interdefensa.argentinaforo.net/t8177-acuerdo-brasil-eau

ACUERDO DE COOPERACION ENTRE CONAE Y LA INSTITUCION EMIRATÍ DE CIENCIA Y TECNOLOGÍA APLICADA (EIAST) DEL GOBIERNO DE DUBAI, EMIRATOS ÁRABES UNIDOS, CONAE, 17/01/2013. Disponible en:

http://www.conae.gov.ar/index.php/espanol/2013/150-acuerdo-emiratos-arabes-20131 
BARTESAGHI, Ignacio, MANGANA, Susana (2014). "El Consejo de Cooperación del Golfo. Las relaciones con el MERCOSUR". MERCOSUR ABC. Dossier de Integración, $\mathrm{N}^{\circ} 19$. Disponible en:

http://www.mercosurabc.com.ar/dossier/2014/N119 14.pdf

BUENO, Pilar, FABANI, Ornela, FERNANDEZ ALONSO, José (2011), “Ambiente, energía y democracia en la región del Golfo Pérsico. Análisis de un dilema de difícil solución". Anuario del Instituto de Relaciones Internacionales, Instituto de Relaciones Internacionales, Universidad Nacional de La Plata (UNLP).

CÁMARA DE COMERCIO ARGENTINO-ÁRABE (2015), “Información sobre países árabes”. Disponible en: http://www.ccaa.com.ar/paises.html

CIA (2016), "The World CIA Factbook". Disponible en:

https://www.cia.gov/library/publications/the-world-factbook/

CIBEIRA, Fernando, “Con el objetivo de seducir a los petrodólares", Página 12, 16/01/2011.

COTELO, Emiliano, “Qué dejó la gira por el mundo árabe”, Espectador.com, 03/05/2007. Disponible en:

http://www.espectador.com/politica/94662/que-dejo-la-gira-por-el-mundo-arabe

ELEISEGHI, Patricio, "Un gigante del petróleo viene por tierras para hacerse de alimentos", IProfesional, 02/11/2010. Disponible en: http://www.iprofesional.com/notas/106516-Un-gigante-del-petrleo-viene-por-tierras-argentinas-parahacerse-de-alimentos

"Emiratos Arabes querem 24 Super Tucanos", 22/01/2015. Disponible en:

http://www.infodefensa.com/latam/2015/01/22/noticia-emirados-arabes-unidos-querem-super-tucanos.html

BANCO MUNDIAL (2015), “Emisiones de CO2 (toneladas métricas per cápita)”. Disponible en: http://datos.bancomundial.org/indicador/EN.ATM.CO2E.PC

FIGUEREDO, Riediger (2014), Política externa brasileira para o mundo árabe: uma análisis dos governos de Lula e Dilma Rousseff, Universidade Federal do Rio Grande do Sul, Faculdade de Ciências Econômicas, Programa de Pos Graduação em Estudos Estatégicos Internacionais, Porto Alegre.

GOES, Francisco, "Vale inaugura no sábado complexo industrial em Oma", Valor, 01/03/2012. Disponible en: http://www.valor.com.br/empresas/2551350/vale-inaugura-no-sabado-complexo-industrial-em-oma

GRANATA, Gabriela, “Otheguy: "La tecnología nuclear argentina tiene un alto reconocimiento". CADIEEL. 17/01/2013. Disponible en: http://www.cadieel.org.ar/esp/nota.php?idContenido =14123

GROSSO, Josefina, MOLDAVAN, Pablo, TODESCA, Nicolás (2009), "Nuevos destinos de las exportaciones argentinas, teoría y evidencia". Ministerio de Economía y Finanzas Públicas. Nota Técnica, 70

"INVAP y TACQNIA crearon la empresa mixta INVANIA", Invap, 06/03/2015. Disponible en:

http://www.invap.com.ar/es/la-empresa/sala-de-prensa/novedades/1270-invap-y-tacqnia-crearon-la-empresa-mixtainvania.html

KRAKOWIAK, Fernando (2014). “La exportación de tecnología nuclear al mundo”. Tecnología nuclear para el desarrollo Edit U-238, Vol.2, N 18. En:http://u-238.com.ar/la-exportacion-de-tecnologia-nuclear-al-mundo/

LUOMI, Mari (2011). "Gulf of Interest: Why Oil Still Dominates Middle Eastern Climate Politics", Journal of Arabian Studies: Arabia, the Gulf, and the Red Sea. Center for International and Regional Studies, Georgetown University School of Foreign Service, Qatar. Disponible en:

http://www.tandfonline.com/doi/pdf/10.1080/21534764. 2011.628499 
MALEK, Caline, "Argentine cooperates with UAE on satellite use to exchange information", The National, 22/02/2014. Disponible en:

http://www.thenational.ae/uae/environment/argentina-cooperates-with-uae-on-satellite-use-to-exchangeinformation

"MERCOSUR y árabes comenzaran a discutir sobre libre comercio", Cronista, 09/05/2005 MINISTERIO DE DESENVOLVIMENTO (2016), "Intercâmbio comercial brasileiro: países e blocos económicos". Disponible en:

http://www.mdic.gov.br/sitio/interna/interna.php?area $=5 \&$ menu=576

MINISTERIO DE RELACIONES EXTERIORES Y CULTO, Información de Prensa Nº28/14, 14/02/2014. Disponible en: https://www.mrecic.gov.ar/mision-de-comercio-e-inversiones-paises-arabes-del-golfo

"Nuestro país entabla lazos con Bahrein", $A B C, 14 / 05 / 2005$. Disponible en:

http://www.abc.com.py/edicion-impresa/politica/nuestro-pais-entabla-lazos-con-bahrein-830594.html

PRESIDENCIA DE LA REPUBLICA DEL PARAGUAY, "Embajada paraguaya en Qatar ya está abierta y aguarda visita del Presidente Cartes", 27/01/2015. Disponible en:

http://www.presidencia.gov.py/noticia/16115-embajada-paraguaya-en-qatar-ya-esta-abierta-y-aguarda-visita-delpresidente-cartes.htm|\#.VqkNPvnhCM8

PRESIDENCIA DE LA REPUBLICA ORIENTAL DEL URUGUAY, "Mujica procura profundizar lazos con Arabia Saudita", 08/10/2010. Disponible en: http://archivo.presidencia.gub.uy/sci/noticias/2010/10/2010100809.htm

RADIC, Sandra (2012), "Fondos de Inversión de países árabes sobrevuelan América Latina para expandirse", Economía y Negocios. Disponible en: http://www.economiaynegocios.cl/noticias /noticias. asp?id=97799

REBOSSIO, Alejandro, "Árabes y sudamericanos estrechan lazos económicos", El País, 07/09/2012. Disponible en: http://blogs.elpais.com/eco-americano/2012/09/\%C3\%A1rabes-y-sudamericanos-estrechan-lazosecon\%C3\%B3micos.html

ROCHA, Alexandre, "Relations with MERCOSUR are strategic for the Gulf", 19/01/2007. Disponible en: http://www2.anba.com.br/noticia/7427347/diplomacy/relations-with-the-mercosur-are-strategic-for-thegulf/?indice $=690$

RUSSELL, Roberto (1990). Política exterior e toma de decisões em América Latina. Buenos Aires: GEL.

SANTISO, Javier, "América Latina y los países árabes, América Economía”, 01/12/2011. Disponible en: http://www.americaeconomia.com/revista/america-latina-y-los-paises-arabes

SECRETARÍA DE COMUNICACIÓN PÚBLICA, PRESIDENCIA DE LA NACIÓN. "Timerman entregó los Premios Exportar y anunció un nuevo récord de ventas al exterior", 21/12/2011. Disponible en:

http://prensa.argentina.ar/2011/12/21/26742-timerman-entrego-los-premios-exportar-y-anuncio-un-nuevo-recordde-ventas-al-exterior.php

SHILOH, Nachum (2012), "The Gulf food security and its Latin American Horizons", Gulf Research Meeting, Cambridge University.

SISTEMA ECONOMICO LATINOAMERICANO Y DEL CARIBE (SELA), “Que es la cooperación sur-sur?”. Disponible en: http://sursur.sela.org/qu\%C3\%A9-es-la-css/conceptos-de-la-cooperaci\%C3\%B3n-sur-sur/ 
SITIO OFICIAL DE LA PROVINCIA DE SANTIAGO DEL ESTERO, "Importante actividad del gobernador Zamora y del príncipe de Bahrein", 22/06/2011. Disponible en: http://www.sde.gov.ar:84/noticias/Noticias.aspx?idNoticia=901

SOARES LIMA, Maria Regina (2005), "A política externa brasileira e os desafíos da cooperação sul-sul”, Revista Brasileira de Política Internacional, Brasilia, Vol. 48, N 1.

SOVEREIGN WEALTH FUNDS INSTITUTE (2015), "Funds Ranking". Disponible en: http://www.swfinstitute.org/fundrankings/

ULRICHSEN, Kristian (2012), "South-South Cooperation and the changing role of the Gulf states", Austral, Vol. 1, Nº 1.

"Uruguay negocia inversión portuaria con Emiratos Árabes Unidos", Cpampa, 12/05/2014. Disponible en:

http://www.cpampa.com/web/cpa/2014/05/uruguay-negocia-inversion-portuaria-con-emiratos-arabes-unidos/

"Uruguay, Saudi Arabia plan for food security", United Press International, 12/10/2010. Diponible en:

http://www.upi.com/Business News/Energy-Industry/2010/10/12/Uruguay-S-Arabia-plan-for-food-

security/91341286879749/

VAGNI, Juan José (2009), "La Cumbre América del Sur-Países Árabes (ASPA): Balances de un acercamiento estratégico", Revista de Estudios Internacionales Mediterráneos (REIM), Nº, junio-diciembre.

VIGEVANI, Tullo, CEPALUNI, Gabriel (2007), “A política externa da Lula Da Silva: a estratégia da autonomía pela diversificação". Contexto Internacional, Rio de Janeiro, Vol. II, N² 